\title{
Primary Adenocarcinoma at Colostomy Site: Report of a Clinical Case
}

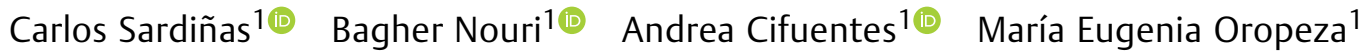 \\ 1 University Hospital of Caracas, Coloproctology Unit, Laboratory of \\ Anorectal Physiology, Caracas, Venezuela \\ Address for correspondence Carlos Sardiñas, University Hospital of \\ Caracas, Coloproctology Unit, Laboratory of Anorectal Physiology, \\ Caracas, Venezuela (e-mail: carloseduardosardinas@gmail.com).
}

J Coloproctol 2022;42(1):102-106.

\author{
Abstract \\ Keywords \\ - colorectal cancer \\ - colostomy \\ - complications of \\ colostomies
}

Colorectal cancer (CRC) is the fourth most frequently diagnosed cancer in the United States and it is found in $17 \%$ of patients thought to have complicated diverticular disease. However, primary adenocarcinoma rarely occur in the colostomy site and the risk of developing malignancy is similar to that of any other colonic segment. Polyps found in CRC screenings can be divided into the following types: hyperplastic polyps, polyps with no malignant potential, adenomatous polyps, polyps with malignant potential, and malignancies. Local complications of the colostomy can appear in the immediate, early, or late postoperative period, with an incidence ranging from 15 to $30 \%$; neoplasia is even less common.

\section{Introduction}

Diverticular disease (DD), a condition associated with the bulging of pouches from the colon surface, is thought to result from increased intraluminal pressure. It was found incidentally during colorectal cancer screening. Diverticulosis and colorectal adenoma or carcinoma is rare among Africans and people from other developing countries. Studies suggest an increasing incidence of DD due to the westernization of dietary habits and lifestyle. ${ }^{1,2}$

Colon cancer is found in $17 \%$ of patients thought to have complicated DD. Studies have suggested that factors like advancing age, low fiber diet, ${ }^{2,3}$ low physical activity, and obesity increases the risk of colorectal cancer. ${ }^{4}$

Colorectal cancer (CRC) is the fourth most frequently diagnosed cancer in the United States and the second most commonly diagnosed cancer in both Hispanic men and women. ${ }^{5,6}$

Polyps found in CRC screenings can be divided into the following types: hyperplastic polyps, polyps with no malig- nant potential, adenomatous polyps, polyps with malignant potential, and malignancies. ${ }^{7}$ Those who have adenomatous polyps are at increased risk for developing cancer compared with those without adenomatous polyps or those with hyperplastic polyps. ${ }^{7}$

Preparing a colostomy with the objective of temporarily or definitively deviating colonic transit is not a risk-free procedure even when performed with the proper surgical technique.

Local complications can appear in the immediate, early, or late postoperative period, with an incidence ranging from 15 to $30 \%$. The most common include necrosis of the colostomy, dermatitis, abscess, bleeding, retraction, stenosis, paraostomy hernia, prolapse, colocutaneous fistula, perforation to the peritoneal cavity, and, less commonly, the appearance of neoplasia. ${ }^{8,9}$

Because of its importance and its low frequency, we report one case of a patient who developed a primary neoplastic lesion in the colostomy, describing its clinical manifestation and the management adopted. received

May 13, 2021

accepted after revision

August 6, 2021

published online

November 29, 2021
DOI https://doi.org/

10.1055/s-0041-1736647.

ISSN 2237-9363.

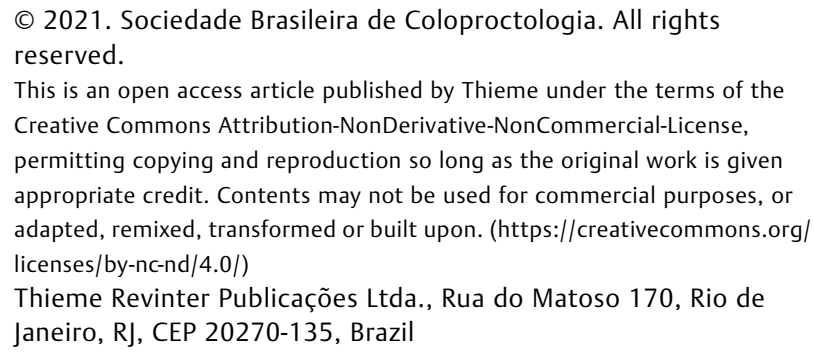

This is an open access article published by Thieme under the terms of the Creative Commons Attribution-NonDerivative-NonCommercial-License, permitting copying and reproduction so long as the original work is given appropriate credit. Contents may not be used for commercial purposes, or adapted, remixed, transformed or built upon. (https://creativecommons.org/ licenses/by-nc-nd/4.0/) Thieme Revinter Publicações Ltda., Rua do Matoso 170, Rio de Janeiro, RJ, CEP 20270-135, Brazil 


\section{Case Report}

A 74-year-old male patient identified the onset of the current disease at $\sim 8$ months, when he presented a colostomy prolapse, concomitant changes in coloration and morphology, as well as outflow of purulent and fetid secretions. As medical history, the patient suffers from high blood pressure treated with nifedipine $30 \mathrm{mg}$ and carvedilol $12.5 \mathrm{mg}$, in addition to laryngeal cancer diagnosed in 2003, which received treatment with chemotherapy and radiotherapy, with total remission of the disease. Among the risk factors, we have a smoking habit from the age of 18 to 58 as well as an accentuated ethyl habit for 16 years, stopping in 2003.

Among the surgical antecedents, his first intervention was in April 2015 due to perforated diverticulitis, for which a Harmant procedure was performed. In August of the same year, he underwent surgery to restore intestinal transit with colorectal anastomosis, which was complicated on the $3^{\text {rd }}$ day when intestinal content was evidenced due to an operative wound, for which he was taken back to the operating table with findings of undamaged anastomosis and jejunum perforation, when $20 \mathrm{~cm}$ of the jejunum was resected, and anastomosis was performed. On the $5^{\text {th }}$ day, he again presented intestinal content due to an operative wound and he underwent surgery with findings of diverticular perforation several centimeters above the previous colorectal anastomosis, for which a transverse colon stoma was made.

It should be noted that, prior to the surgery for autologous restitution of the intestinal transit, in June 2015, a colonoscopy was performed with evidence of colonic polyposis (-Fig. 1). A polypectomy was performed, with the pathological findings of hyperplastic polyps in the ascending colon and rectum and tubular adenoma in the transverse colon. In August 2016, gastroscopy and colonoscopy were performed again; the former only presented pharyngeal diverticulum and congestive gastritis of the body and fundus, and the latter reported colon surgery on a distal colon polyposis line, on a transverse colon injury in ostomy and colon polyposis, so the patient was scheduled to undergo a polypectomy, which was performed in October 2016 with pathological findings of tubular adenoma.

In view of these facts, the patient consulted the coloproctology unit of the university hospital for presenting colostomy prolapse and wished to restore intestinal transit. The physical examination evaluated the patient as being in regular general conditions: Cardiopulmonary: without alteration; abdomen: symmetrical, with prolapse of the transverse colostomy of $\sim 20 \mathrm{~cm}$, presenting within it a mass of $5 \times 8 \mathrm{~cm}$, friable, irregular, with poorly defined edges, neoplastic appearance, necrotic patches, and fetid discharge

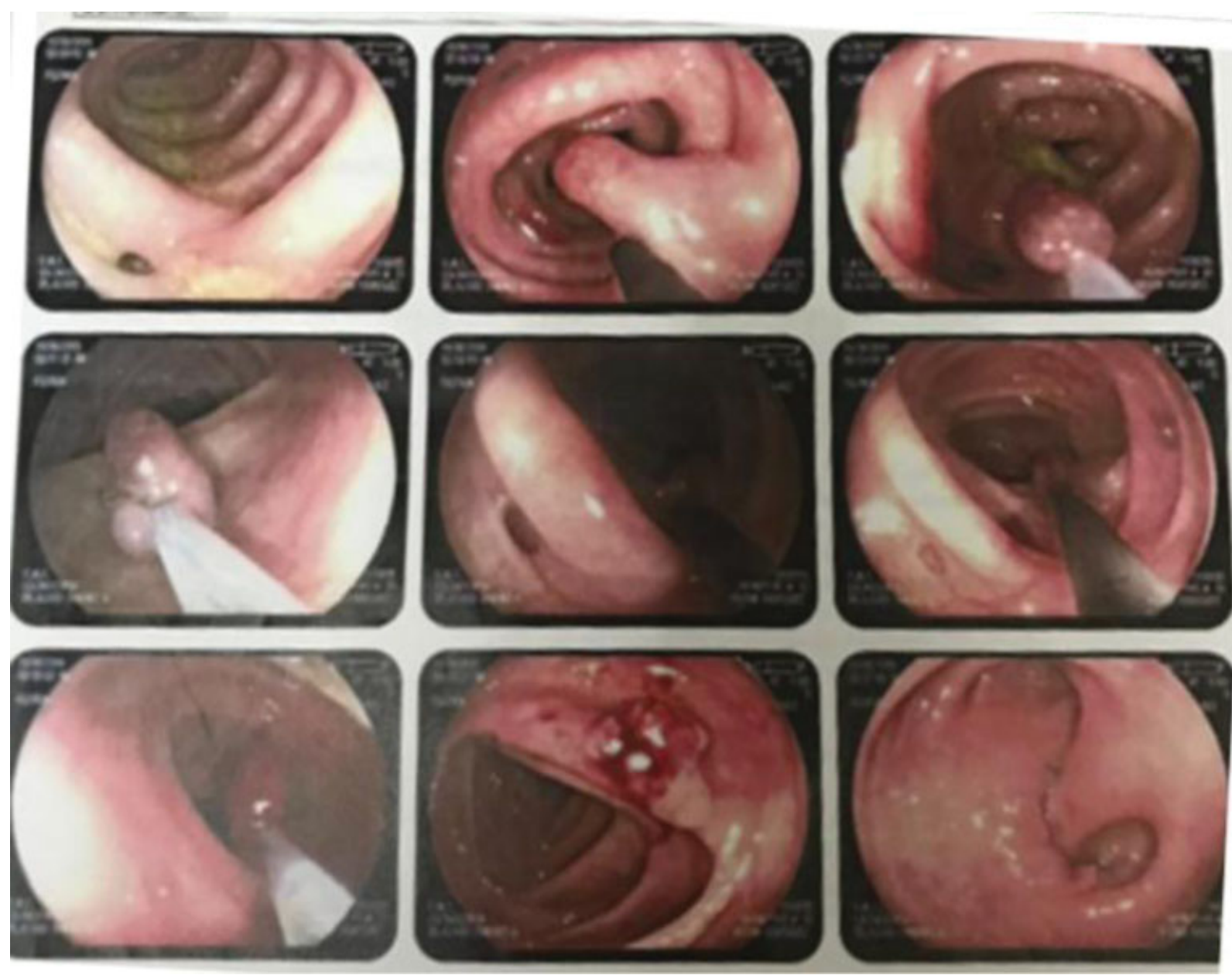

Figure 1 Colonoscopy and polypectomy. 


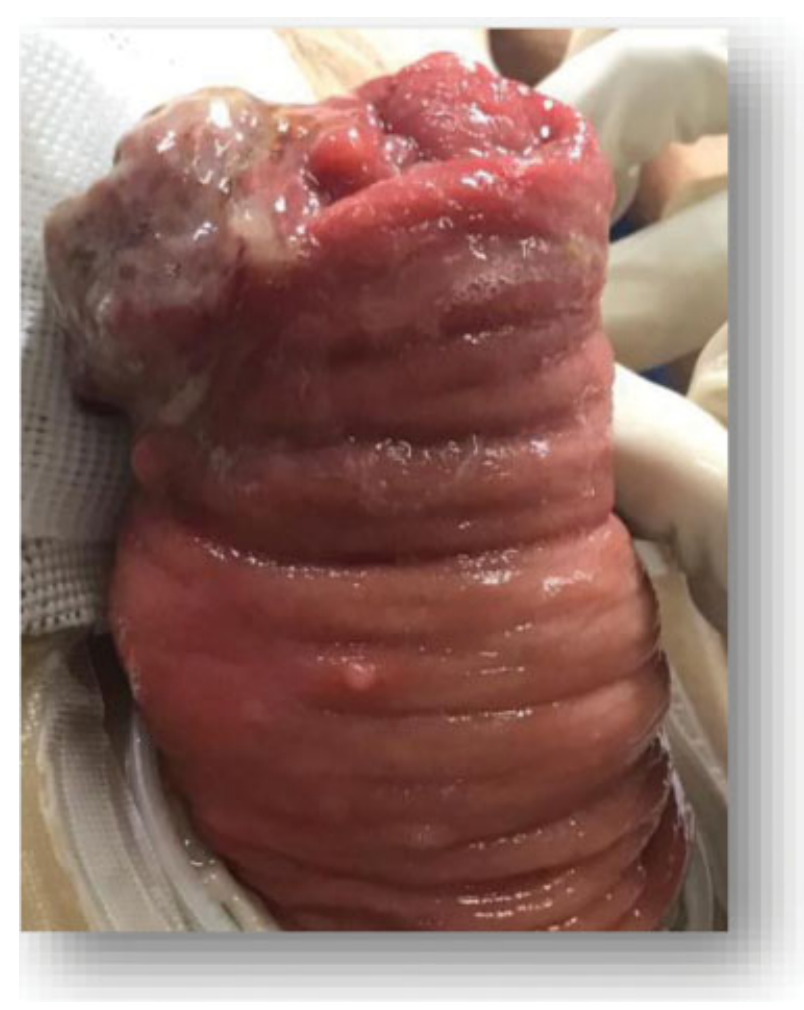

Figures 2 and 3 Prolapsed ostomy with presence of tumor lesion.

(-Figs. 2 and 3), in addition to an infraumbilical midline eventration of $5 \times 4 \mathrm{~cm}$, without inguinal lymphadenopathy. At the proctological level, we found anal margin without lesions; the digital rectal examination found that the sphincter retained tone, good puborectal muscle response, no palpable lesions, and anoscopy without alteration.

A lesion biopsy was taken, which reported moderately differentiated adenocarcinoma with neuroendocrine features, and a colonoscopy was performed in May 2019, which reported polyposis of the right colon, proctitis, and transverse ostomy prolapse. Among the studies performed, we have computed tomography (CT) of the chest, abdomen, and pelvis with double contrast, which concludes in signs of COPD of the pulmonary emphysema, a calcified pulmonary nodule of residual appearance in the left pulmonary apex, ostomy prolapse, and pericolonic fat through its orifice, in addition to inflammatory-looking left periaortic lymphadenopathy. Laboratory samples showed no alteration and CEA at $1.4 \mathrm{ng} / \mathrm{dl}$.

Having the results of all the studies requested, it was decided on May 22, 2019, to take the patient to the operating table and perform a total colectomy in addition to an ileoproctoanastomis with a $29 \mathrm{~mm}$ circular self-suturing EEA with the following intraoperative findings: severe adherent syndrome, intestinal fistula (-Fig.4), and Chinese ink marking of endoscopic studies (-Fig. 5). He had satisfactory evolution, started a diet on the $3^{\text {rd }}$ day and was discharged on the $6^{\text {th }}$ day. He attended three weekly check-ups where no complications developed.

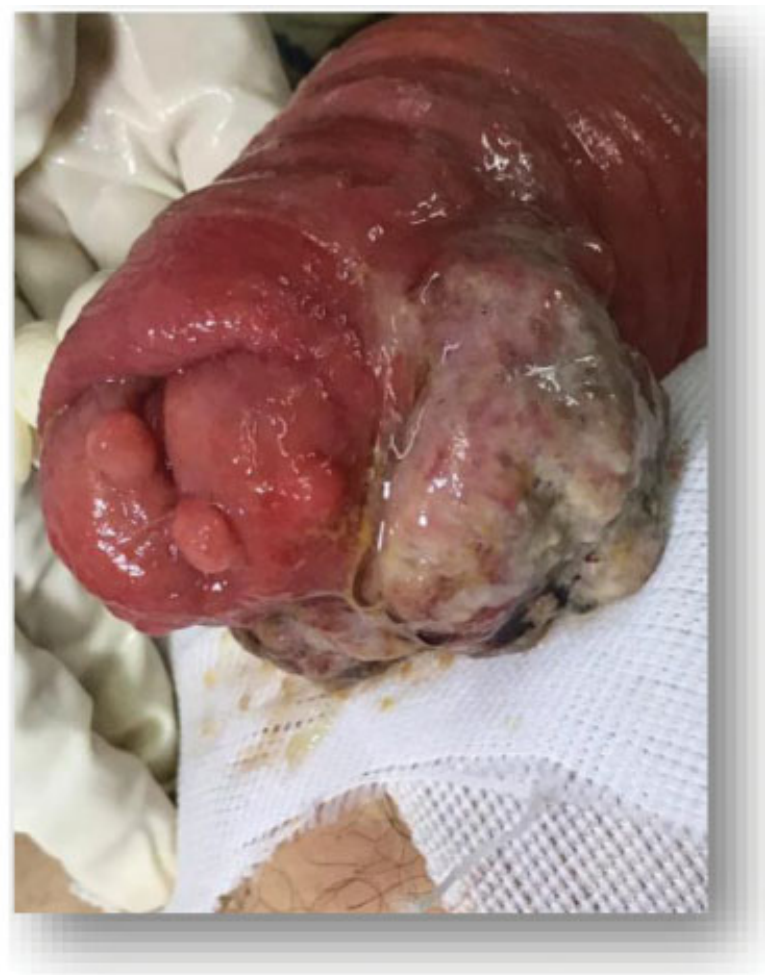

The biopsy of the extracted piece revealed an moderately differentiated infiltrating ulcerated adenocarcinoma with neuroendocrine features resulting from a transverse colostomy in the loop, resection borders free of neoplasia, 41

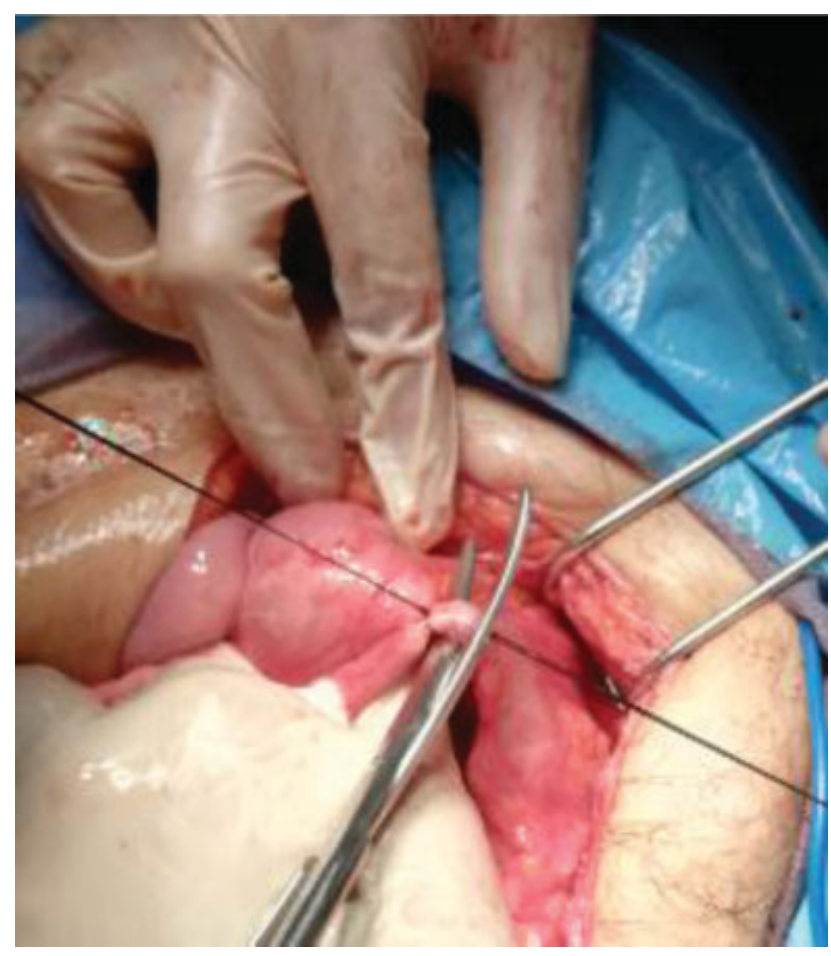

Figure 4 Intestinal fistula. 


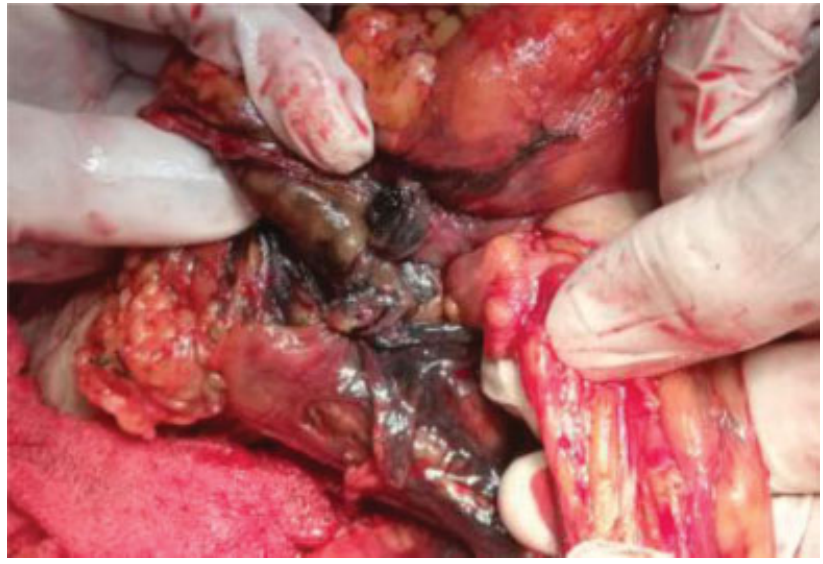

Figure 5 Chinese ink marking of endoscopic studies.

lymph nodes without evidence of metastasis, numerous Entamoeba spp. Trophozoites (-Fig. 6), multiple hyperplastic polyps (-Fig. 7), sessile serrated adenoma polyp, tubular adenomas, and uncomplicated diverticular disease.

\section{Discussion}

We know that 2 years is the minimum time necessary for an adenomatous polyp to change into adenocarcinoma; therefore, all neoplasms developed during this period should not be termed metachronous but should be defined as synchronous to the primary tumor. ${ }^{10}$ The presence of carcinoma in the colostomy site is not common; nevertheless, its appearance can occur with time and progresses with high rates of morbimortality. ${ }^{11,12}$

Considering that colostomy is an exteriorized segment of the colon with the same predisposing and provoking factors for development of a primary colonic tumor, it is accepted that the neoplastic risk is similar to that of any other portion of the colon, and it is markedly elevated when associated with a metachronic lesion. ${ }^{13}$

Colonic amebiasis can mimic colon carcinoma clinically, radiologically, and endoscopically. ${ }^{14,15}$ Conversely, coexisting

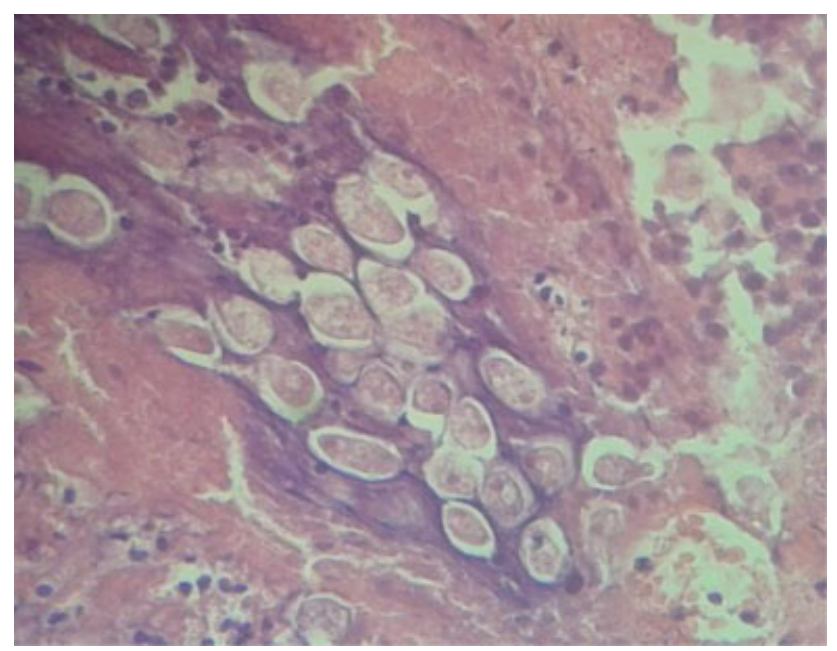

Figure 6 Entamoeba spp and Trophozoites.

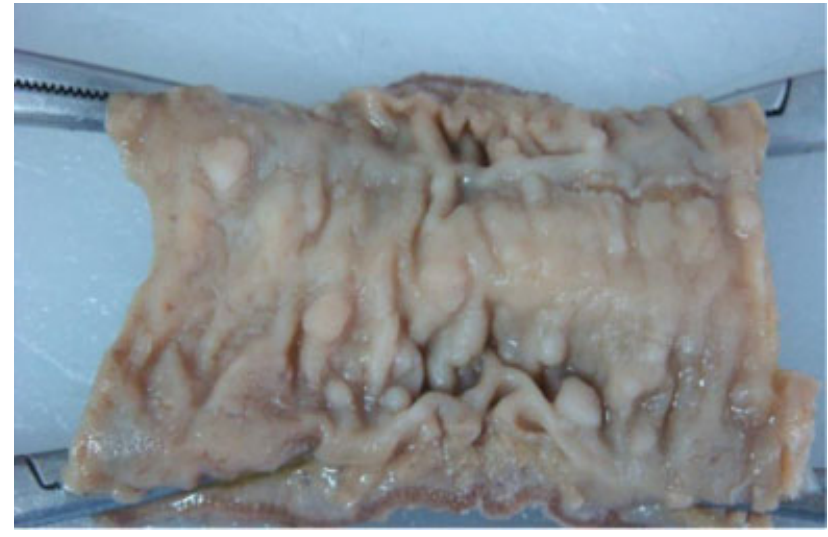

Figure 7 Multiple hyperplastic polyps.

amebiasis and carcinoma are exceedingly rare. ${ }^{16-20}$ In 2 African studies, colorectal carcinoma was found to be associated with intestinal amebiasis in 6.1 and $6.5 \%$ of the cases. ${ }^{16,17}$ Furthermore, five cases of cervical, perineal, sigmoid and pulmonary carcinomas colonized by E. histolytica have been described in three case reports. ${ }^{18,19}$ However, to our knowledge, apart from a single case study dated from $1963,{ }^{20}$ the unique coincidence of colon carcinoma and amebomas has not been published previously in the literature.

Primary adenocarcinoma arising from an ileostomy is rare. The first case of primary adenocarcinoma following proctocolectomy for ulcerative colitis was reported by Sigler et al. $1969 .^{21}$ The first case of ileostomy adenocarcinoma following proctectomy for familial adenomatous polyposis was reported by Roth et al. in $1982 .^{22}$ The incidence of small bowel malignancy in the general population is 0.7 per $100,000 .^{23}$ The ileum is most frequently involved (49\%) followed by jejunum (29\%) and duodenum (22\%). In contrast, an adenocarcinoma of the small bowel is the least commonly found in the ileum (22\%), followed by the jejunum (38\%) and the duodenum (40\%). Suarez et al. estimated the incidence of ileostomy carcinomas in Britain to be between 2 and 4 per 1,000 ileostomies. $^{24}$

Conflict of Interest

None declared.

\section{References}

1 Korzenik JR. Case closed? Diverticulitis: epidemiology and fiber. J Clin Gastroenterol 2006;40(Suppl 3):S112-S116

2 Painter NS. The cause of diverticular disease of the colon, its symptoms and its complications. Review and hypothesis. J R Coll Surg Edinb 1985;30(02):118-122

3 Aldoori WH, Giovannucci EL, Rimm EB, et al. Prospective study of physical activity and the risk of symptomatic diverticular disease in men. Gut 1995;36(02):276-282

4 Strate LL, Liu YL, Aldoori WH, Giovannucci EL. Physical activity decreases diverticular complications. Am J Gastroenterol 2009; 104(05):1221-1230

5 U.S. Cancer Statistic Working Group. United States Cancer Statistics: 1999-2013 incidence and mortality web-based report. 2016http://www.cdc.gov/uscs. Accessed 3 Feb 2017. 
6 American Cancer Society. Cancer facts \& figures for Hispanics/ Latinos 2015-2017. Atlanta, GA: American Cancer Society; 2015

7 Lieberman DA, Rex DK, Winawer SJ, Giardiello FM, Johnson DA, Levin TR. Guidelines for colonoscopy surveillance after screening and polypectomy: a consensus update by the US Multi-Society Task Force on Colorectal Cancer. Gastroenterology 2012;143(03):844-857

8 Nour S, Beck J, Stringer MD. Colostomy complications in infants and children. Ann R Coll Surg Engl 1996;78(06):526-530

9 Park JJ, Del Pino A, Orsay CP, et al. Stoma complications. Dis Colon Rectum 1999;42(12):1575-1580

10 Muto T, Bussey HJ, Morson BC. The evolution of cancer of the colon and rectum. Cancer 1975;36(06):2251-2270

11 Corman ML. Intestinal stoma. In: Colon and rectal surgery. 4-ed. Los Angeles1998:1264-1319

12 Shibuya T, Uchiyama K, Kokuma M, et al. Metachronous adenocarcinoma occurring at a colostomy site after abdominoperineal resection for rectal carcinoma. J Gastroenterol 2002;37(05):387-390

13 Carey PD, Suvarna SK, Baloch KG, Guillou PJ, Monson JR. Primary adenocarcinoma in an ileostomy: a late complication of surgery for ulcerative colitis. Surgery 1993;113(06):712-715

14 Moorchung N, Singh V, Srinivas V, Jaiswal SS, Singh G. Caecal amebic colitis mimicking obstructing right sided colonic carcinoma with liver metastases: a rare case. J Cancer Res Ther 2014;10 (02):440-442

15 Ooi BS, Seow-Choen F. Endoscopic view of rectal amebiasis mimicking a carcinoma. Tech Coloproctol 2003;7(01):51-53
16 Ojo OS, Odesanmi WO, Akinola OO. The surgical pathology of colorectal carcinomas in Nigerians. Trop Gastroenterol 1992;13 (02):64-69

17 Kenda JF. Cancer of the large bowel in the African: a 15-year survey at Kinshasa University Hospital, Zaïre. Br J Surg 1976;63 (12):966-968

18 Mhlanga BR, Lanoie LO, Norris HJ, Lack EE, Connor DH. Amebiasis complicating carcinomas: a diagnostic dilemma. Am J Trop Med Hyg 1992;46(06):759-764

19 Zhu H, Min X, Li S, Feng M, Zhang G, Yi X. Amebic lung abscess with coexisting lung adenocarcinoma: a unusual case of amebiasis. Int J Clin Exp Pathol 2014;7(11):8251-8254

20 Cannavo L. Sigmoid carcinoma in a patient with chronic amoebiasis or pseudoneoplastic amoebic granuloma (amoeboma). Panminerva Med 1963;5:159-162

21 Sigler L, Jedd FL. Adenocarcinoma of the ileostomy occurring after colectomy for ulcerative colitis: report of a case. Dis Colon Rectum 1969;12(01):45-48

22 Roth JA, Logio T. Carcinoma arising in an ileostomy stoma: an unusual complication of adenomatous polyposis coli. Cancer 1982;49(10):2180-2184

23 Barclay TH, Schapira DV. Malignant tumors of the small intestine. Cancer 1983;51(05):878-881

24 Suarez V, Alexander-Williams J, O'Connor HJ, et al. Carcinoma developing in ileostomies after 25 or more years. Gastroenterology 1988;95(01):205-208 